\title{
Interfacial Behaviors of Ionic Liquids and Asphaltenes at Oil-Water Interface: Dynamic Diffusion and Interfacially Competitive Adsorption
}

Zhidan Jia ${ }^{1,2 \zeta}$, Zhen Niu ${ }^{3 \zeta}$, Ziqi Yang ${ }^{1,2}$, Xingang Li ${ }^{1,2,4}$, Junyan Wang ${ }^{1,2}$, Xiao He ${ }^{3}$, Hong Sui ${ }^{1,2,4}$, Lin $\mathrm{He}^{1,2 *}$

1 School of Chemical Engineering and Technology, Tianjin University, 300072 Tianjin, China

2 National Engineering Research Centre for Distillation Technology, 300072 Tianjin, China

3 Department of Chemical and Materials Engineering, University of Alberta, Edmonton, Alberta T6G 2V4, Canada

4 Collaborative Innovation Center of Chemical Science and Engineering, 300072 Tianjin, China

* Correspondence: $\underline{\text { linhe@,tju.edu.cn; }}$

$\zeta$ These two authors contribute equally to this work. 

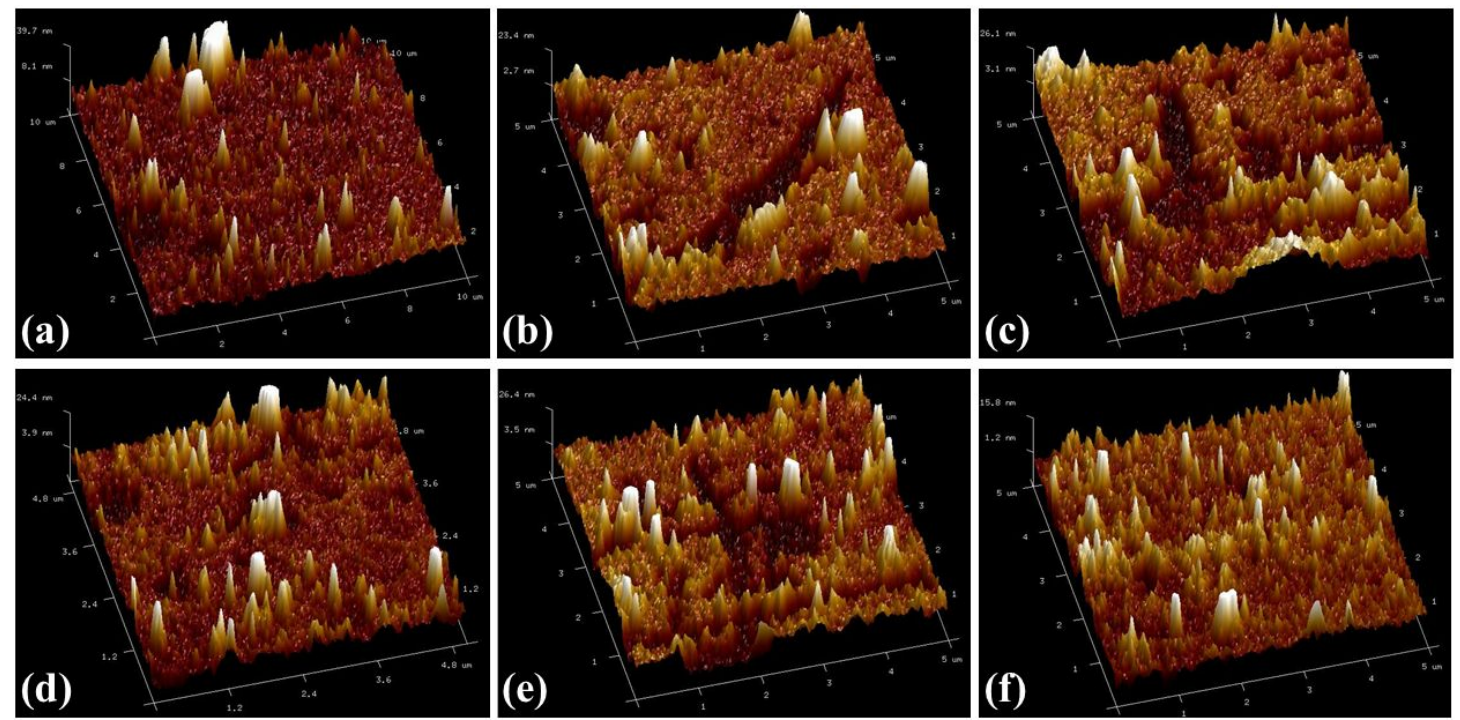

Figure S1. AFM topographs of the interfacial films under different conditions: (a) asphaltene interfacial film; (b) with the addition of $\left[\mathrm{C}_{8} \mathrm{mim}\right][\mathrm{Br}]$ in spreading protocol; (c) with the addition of $\left[\mathrm{C}_{12} \mathrm{mim}\right][\mathrm{Br}]$ in spreading protocol; (d) with the addition of $\left[\mathrm{C}_{8} \mathrm{mim}\right][\mathrm{Br}]$ in diffusion protocol; (e) with the addition of $\left[\mathrm{C}_{12} \mathrm{mim}\right][\mathrm{Br}]$ in diffusion protocol; (f) silicon wafer surface. 